\title{
AVALIAÇÃO DA IMAGEM DE UM DESTINO TURÍSTICO NO INSTAGRAM
}

\author{
ASSESSING A TOURISM DESTINATION IMAGE ON INSTAGRAM \\ EVALUACIÓN DE LA IMAGEN DE UN DESTINO TURÍSTICO EN INSTAGRAM \\ Fabrícia Durieux Zucco
}

Doutora em Administração pela Universidade Nove de Julho (UNINOVE). Professora titular da UNIVALI (Universidade do Vale do Itajaí) e da FURB (Universidade Regional de Blumenau)

fabriciazucco@hotmail.com

Orcid: https://orcid.org/0000-0001-5538-1195

\section{Melise de Lima Pereira}

Mestre em Turismo e Hotelaria pela Universidade do Vale do Itajaí

Doutoranda em Turismo e Hotelaria pela Universidade do Vale do Itajaí, com bolsa CAPES/PROSUC

Professora Assistente no Curso de Bacharelado em Turismo, do Instituto de Ciências Humanas e da Informação, da Universidade Federal do Rio Grande (FURG), Campus Santa Vitória do Palmar-RS.

melisedelimapereira@gmail.com

Orcid: 0000-0003-1904-8429

\section{Pablo Flôres Limberger}

Doutor em Turismo e Hotelaria pela Universidade do Vale do Itajaí (UNIVALI)

Professor da UNIVALI (Universidade do Vale do Itajaí) no Programa de Pós- Graduação em Turismo e Hotelaria

pablofl@univali.br

Orcid: https://orcid.org/0000-0001-6814-6020

\section{Christian Daniel Falaster}

Doutor em Administração pela Universidade Nove de Julho (2017)

Professor Universitário do Quadro Permanente, da Fundação Universidade Regional de Blumenau (FURB).

christianfalaster@gmail.com

Orcid: http://orcid.org/0000-0001-9502-4475

RESUMO: Com os avanços tecnológicos, as imagens postadas nas redes sociais de fotografia (Instagram) são utilizadas como ferramentas de avaliação pelos turistas, desta forma, o gerenciamento destas ferramentas são essenciais para os destinos turísticos. O objetivo desta pesquisa é avaliar a imagem do destino turístico 
Salvador, Bahia, Brasil, a partir das publicações de uma rede social de fotografia, o Instagram. O presente trabalho analisou 400 imagens marcadas no Instagram com a hashtag \#salvador, sendo que para a categorização das imagens coletadas foram utilizadas as dimensões da imagem cognitiva e motivacionais de Baloglu e Mccleary (1999). A pesquisa é exploratória, com abordagem qualitativa e quantitativa. A coleta de dados foi realizada, de forma aleatória, na rede social Instagram, por meio do software Seekr Monitor, uma ferramenta para monitoramento e gestão das mídias sociais. Por meio de análise de regressão linear múltipla, identificou-se a existência de relações causais positivas e negativas entre as dimensões da imagem e motivacionais do destino turístico e o número de curtidas por seguidor no Instagram. Os resultados indicam que as Destination Management Organization (DMOs) de Salvador (BA) devem direcionar seus esforços promocionais nas redes sociais virtuais, envolvendo a formação da imagem de valor ao ambiente, em vez de comercializar o destino por meio dos apelos motivacionais do prestígio.

\section{PALAVRAS-CHAVE: Gestão; Destino Turístico; Imagem; Instagram}

ABSTRACT: With the technological advances, the images posted on the social photography networks (instagram) are used as evaluation tools by tourists. Therefore, managing these tools is essential for tourist destinations. The purpose of this research is to evaluate the image of the tourist destination of Salvador, in the Brazilian state of Bahia, based on the publications of a social photography network, Instagram. The present work analyzed 400 images marked on Instagram with the hashtag \#salvador. The dimensions of cognitive and motivational image of Baloglu and Mccleary (1999) were used to categorize the collected images. The research is exploratory, with a qualitative and quantitative approach. The data collection was carried out in random form, on the social network Instagram, through the software Seekr Monitor, a tool for monitoring and managing social media. Through multiple linear regression analysis, we identified the existence of positive and negative causal relationships between the image and motivational dimensions of the tourism destination, and the number of likes by followers on Instagram. The results indicate that the Destination Management Organization (DMOs) of Salvador (BA) should focus their promotional efforts on virtual social networks, involving the formation of an image of value to the environment, instead of marketing the destination through the motivational appeals of prestige.

KEYWORDS: Management; Tourist Destination; Image; Instagram

RESUMEN: Con los avances tecnológicos, las imágenes publicadas en las redes sociales de fotografía (Instagram) son utilizadas como herramientas de evaluación por los turistas, de esta forma, el gerenciamiento de estos tipos de herramientas son esenciales para los destinos turísticos. El objetivo de esta investigación es evaluar la imagen del destino turístico Salvador, Bahía, Brasil, a partir de las publicaciones de una red social de fotografía, el Instagram. El presente trabajo analizó 400 imágenes marcadas en Instagram con el hashtag \#salvador, siendo que para la categorización de las imágenes recolectadas fueron utilizadas las dimensiones de la imagen cognitiva y motivacionales de Baloglu y Mccleary (1999). La investigación es exploratoria, con abordaje cualitativa y cuantitativa. La recolección de datos fue realizada, de forma aleatoria, en la red social Instagram, por medio del software Seekr Monitor, una herramienta para monitoreo y gestión de los medios sociales. Por medio de análisis de regresión linear múltiple, se identificó la existencia de relaciones casuales positivas y negativas entre las dimensiones de la imagen y motivacionales del destino turístico y el número de "me gusta" por seguidor en Instagram. Los resultados indican que las Destination Management Organization (DMOs) de Salvador (BA) deben dirigir sus esfuerzos promocionales a las redes sociales virtuales, incluyendo la formación de la imagen de valor al ambiente, en vez de comercializar el destino por medio de los llamados motivacionales del prestigio.

PALABRAS CLAVE: Gestión; Destino Turístico; Imagen; Instagram.

\section{INTRODUÇÃO}

A internet modificou o processo de escolha do destino e a busca de informações turísticas. A fotografia de viagem desempenha uma multiplicidade de funções no turismo (Lo,
Mckercher, Lo, Cheung, \& Law, 2011). Frente ao crescente investimento em posicionamento do destino turístico, as pesquisas sobre a imagem de destino estão em evidência (Pike, 2007), sendo que as mídias sociais e as fotografias passaram a ser utilizadas como ferramentas de avaliação da 
imagem de destino (Awaritefe, 2005), alteração do olhar do turista e da experiência turística (Sheungting \& Mckercher, 2015).

A temática voltada à imagem de destino vem sendo objeto de estudo de diversas pesquisas em turismo. Os pesquisadores apresentam definições conceituais e metodológicas, integrando as abordagens do turismo, a publicidade e a paisagem, com vistas a contribuir para uma teoria evolutiva sobre a formação da imagem de destino (MacKay \& Fesenmaier, 1997); outros investigadores analisam o construto teórico imagem e as suas dimensões (Baloglu \& McCleary, 1999); existem os que apresentam uma abordagem integrada para avaliar as relações estruturais da imagem de destino, da satisfação geral e da lealdade do destino (Chi \& Qu, 2008); há os que analisam o efeito das motivações psicológicas, dos valores culturais e das características demográficas dos indivíduos sobre a formação da imagem de marca dos destinos (Gutiérrez \& Bosque, 2010).

Chagas (2008) identificou na sua pesquisa seis grandes grupos temáticos de investigações sobre a imagem em destino turístico, sendo estes: Conceitos e dimensões; Processos de formação; Avaliação e medição; Distância e mudanças na imagem ao longo do tempo, Papel ativo e passivo da comunidade na formação da imagem; Políticas e gerenciamento da imagem do destino.

Estudos mais recentes mostram que as redes sociais virtuais são um dos principais meios de comunicação e compartilhamento de fotografias de viagens (Lo et al., 2011). Pesquisadores apontam que a construção da imagem dos destinos turísticos em meios de comunicação social pode ser fortalecida por meio do engajamento dos usuários das mídias sociais (Stepaniuk, 2015). Diante disso, avaliar o uso da fotografia turística, identificar o processo de seleção e a publicação das fotografias on-line se tornaram objeto de estudo nos últimos anos (Sheungting \& Mckercher, 2015).

Apesar do aumento do interesse pelo processo de seleção e da publicação das fotografias on-line por parte dos pesquisadores do turismo, pode-se notar uma lacuna referente ao estudo das redes sociais virtuais e a da imagem de destino turístico. Nesse contexto, vislumbra-se a relevância deste estudo, na medida em que se busca ampliar os estudos sobre a formação da imagem de destino turístico projetada nas mídias sociais virtuais.
Em decorrência do que foi apresentado até o momento, a presente investigação busca avaliar a imagem do destino turístico Salvador, Bahia, Brasil, a partir das publicações de uma rede social de fotografia, o Instagram. Escolheu-se o Instagram por ser um aplicativo projetado para compartilhar fotos e é descrito no Instagram FAQ (2017) como "uma maneira divertida e peculiar de compartilhar sua vida com amigos através de uma série de imagens" (parágrafo 2). Nota-se que a rede social de fotografia Instagram é uma maneira dos turistas propagarem imagens do mundo por meio de fotografias on-line.

A pesquisa fornece contribuição teórica e metodológica ao tema, visto que busca construir um modelo para avaliar a imagem de destino turístico projetada nas mídias sociais virtuais, corroborando para o avanço das discussões sobre as mídias sociais e a fotografia digital, conforme exposto na pesquisa de Sheungting e Mckercher (2015). Além disso, apresenta contribuição teórica e empírica, ao avaliar quais são as dimensões da imagem cognitiva e as dimensões motivacionais (Baloglu \& McCleary, 1999) que influenciam o construto geral da imagem do destino turístico Salvador (BA), a partir das fotografias publicadas na rede social Instagram. Essas contribuições servirão para o avanço do conhecimento científico sobre a relação entre os construtos: imagem de destino, redes sociais virtuais e fotografias. Ademais, os resultados poderão auxiliar as destination management organization (DMOs), os gestores públicos e privados do destino turístico Salvador (BA) a formular estratégias para o posicionamento e à comunicação da imagem do destino.

Sendo assim, a pergunta que norteia esta pesquisa é a seguinte: "Qual a imagem do destino turístico Salvador (BA) projetada no Instagram?”

\section{FUNDAMENTAÇÃO TEÓRICA}

A fundamentação teórica está dividida em duas partes. Inicialmente, será discutido sobre a temática voltada à imagem de destino e a relação com as motivações turísticas, apresentando os estudos mais recentes, em âmbito internacional, com as evidências teóricas e empíricas da relação entre esses construtos. Na segunda parte, será discutido a respeito das redes sociais virtuais e as fotografias, vistas como elementos modificadores do olhar do turista. 


\section{IMAGEM DE DESTINO E MOTIVAÇÕES TURÍSTICAS}

As pesquisas sobre imagem de destino têm sido recorrentes devido ao crescente investimento em posicionamento do destino diante dos mercados competitivos (Pike, 2007). A imagem influencia na escolha do destino e, também, contribui para a satisfação dos turistas com suas experiências de viagem, podendo condicionar o processo de decisão do turista (Chi \& Qu, 2008). Para que a comercialização do destino turístico seja eficaz, é preciso compreender as motivações dos consumidores turistas (Fodness, 1994).

O estudo seminal de Baloglu e McCleary (1999) discorre sobre o construto teórico imagem de destino e suas dimensões. Os autores conceituam a imagem como "um construto atitudinal constituído por uma representação mental de crenças, sentimentos e impressão geral de um indivíduo sobre um objeto ou destino" (Baloglu \& McCleary, 1999, p. 870). A referida definição enfatiza principalmente os componentes cognitivos da imagem, referindo-se às crenças e ao conhecimento sobre os atributos mensuráveis do destino.

Para Baloglu e McCleary (1999), a imagem de um destino está altamente relacionada com os benefícios turísticos, evidenciando que a relação entre as motivações e a imagem de destino deve ser explorada para melhor compreender o comportamento do turista. Os resultados da pesquisa empírica, realizada em quatro países: Turquia, Grécia, Itália e Egito, mostraram que as dimensões motivacionais conhecimento, prestígio e social impactam diretamente na imagem do destino, por outro lado, a aventura possui impacto indireto. Os autores destacam que o apelo para as motivações pode ser uma maneira de construir e manter a imagem do destino turístico.

Os turistas decidem sair, viajar, conhecer novos lugares, em virtude de diferentes motivos ou razões. Crompton \& McKay (1997) destacam que a motivação é um fator interno, o qual integra o comportamento de uma pessoa. Tomar a decisão de visitar um destino é uma ação desencadeada por um desejo de satisfazer uma necessidade. Os motivos são o ponto de partida para o processo de decisão. Beerli \& Martín (2004) afirmam que a imagem percebida pelo turista pós-visita ao destino é formada por meio da imagem projetada pelo destino e pelas necessidades do turista, suas diferentes motivações, seu conhecimento prévio, suas preferências e principalmente suas características pessoais.

A pesquisa de Fodness (1994) contribuiu para o avanço do conhecimento científico ao desenvolver um instrumento de mensuração da motivação turística, referindo-se às viagens de lazer. Foram encontradas quatro dimensões das motivações turísticas a partir da experiência de férias: a primeira, função de conhecimento e utilização das viagens de lazer, foi composta de temas relacionados à ideia de escapar da vida cotidiana, dando ênfase em afastar-se das pressões e das responsabilidades; a segunda, função social do lazer, apresenta os aspectos sociais da experiência de férias, como: visitar amigos e parentes e compartilhar experiências familiares; a terceira, função expressão do valor da viagem de lazer, composta de temas centrados na expressão dos valores pessoais dos indivíduos; por fim, a quarta dimensão é semelhante à primeira, remete à função utilitária da viagem de lazer, mas dando ênfase à maximização das recompensas da vida. Os resultados e as conclusões desse estudo apoiam a tentativa de uma explicação funcional da motivação turística.

Os estudos mais recentes buscam apresentar as evidências teóricas e empíricas sobre as relações causais entre alguns construtos. A pesquisa de Whang, Yong \& Ko (2016) examinou o efeito do envolvimento da cultura pop na formação e na percepção da imagem de destino, analisando a diferença entre modelos estruturais na China e na Rússia. Olague (2016) avaliou os efeitos determinantes da motivação da viagem sobre a imagem percebida pelos turistas da cidade de Monterrey, no México. A pesquisa apresentou contribuições gerencias para o desenvolvimento de estratégias no destino turístico. Abdel, Fayed, Wafik, \& Gerges (2016) evidenciam que o comportamento do turista pode ser uma construção agregada, envolvendo a motivação para a escolha do destino, a experiência no local, a satisfação e a lealdade ao destino. Os autores destacam que identificar as motivações dos turistas/visitantes e aumentar a qualidade do serviço são fatores viáveis para o desempenho competitivo dos destinos.

O estudo de Whang et al. (2016) inova ao aplicar o conceito de envolvimento (situacional e duradouro) com a cultura pop ao discurso do turismo. Em tempos de tecnologia da informação 
avançada, o conhecimento pode ser acessado com facilidade, e as informações de boca a boca virtual são facilmente alcançáveis. $\mathrm{O}$ fenômeno mundial da cultura pop coreana pode ter influência sobre a atividade turística, gerando transições e impacto social, tendo em vista que as mídias sociais virtuais levam à disseminação dessa cultura estrangeira. Diante desse contexto, os autores inter-relacionam o construto envolvimento com a cultura pop (o caso da cultura pop coreana), a imagem do destino turístico e a intenção de visitar, comparando a relação estrutural entre a China e a Rússia, com base nas motivações de viagem, frente ao crescente número de turistas desses países que visitam a Coréia. Os resultados apontam que o envolvimento dos chineses e russos com a cultura pop coreana apresenta uma relação positiva com a imagem e a motivação turística para visitar o destino.

A pesquisa de Olague (2016) identificou aspectos relevantes que afetam o comportamento do turista. $O$ autor utilizou a técnica de modelagem de equações estruturais para testar o modelo de mínimos quadrados parciais (PLS), confirmando a relação causal estabelecida entre a motivação da viagem e a imagem de destino. $\mathrm{O}$ artigo apresentou evidências empíricas que reforçam os resultados encontrados por Baloglu e McCleary (1999), porém analisou o contexto de uma cidade metropolitana. Notou-se que os turistas são motivados a viajar para a cidade de Monterrey, no México, em busca de locais históricos e culturais, para visitar as principais atrações turísticas e experimentar a atmosfera de uma cidade metropolitana. Quanto à avaliação da imagem do destino, destacaram-se o caráter divertido e a personalidade agradável que remetem à imagem afetiva do destino e, também, por ser um destino adequado para a família, possuindo belas paisagens (imagem cognitiva). $\mathrm{O}$ autor concluiu que o método de modelagem de mínimos quadrados parciais (PLS) é uma maneira de obter informações válidas e confiáveis para a tomada de decisões da gestão turística do destino.

\section{REDES SOCIAIS VIRTUAIS E FOTOGRAFIAS}

Diante da crescente ênfase da publicidade, as organizações de marketing e promoção dos destinos turísticos (DMOs) oferecem informações sobre as atrações de um destino, eventos e instalações para os turistas/visitantes em potencial. Esse tipo de informação é comercializado por meio de brochuras e websites (Singh \& Formica, 2006) hospitality organizations have traditionally been reluctant to utilize Information Communication Technology (ICT. No entanto, atualmente, os turistas em todo o mundo estão utilizando a internet para selecionar um destino, enfatizando a competitiva publicidade de destinos turísticos (Buhalis, 2000). Para Gartner (1993) e Baloglu e McCleary (1999), as DMOs podem induzir uma imagem favorável dos destinos turísticos nas mentes dos consumidores.

A pesquisa de Singh e Formica (2006) avaliou o grau de congruência da imagem de destino pictórica retratada por DMOs nos estados do Nordeste dos Estados Unidos. Os materiais promocionais selecionados para análise foram as brochuras enviadas pelas organizações de turismo aos consumidores mediante solicitação, e os sites oficiais das empresas. Os resultados mostraram alta congruência negativa entre ambas as mídias, mostrando que as DMOs não estão retratando a mesma imagem de destino entre as brochuras e os websites.

As fotografias podem ser utilizadas como uma ferramenta de avaliação da imagem de destino, a partir da visão dos turistas (Awaritefe, 2005). Lo et al. (2011) discutem as implicações para a promoção do destino, por meio do uso da fotografia on-line. As mídias sociais e as fotografias digitais são vistas como uma maneira de redefinir o olhar do turista e, assim, modificar a experiência turística (Sheungting \& Mckercher, 2015), além de fortalecer o engajamento de usuários de mídia social (Stepaniuk, 2015).

Awaritefe (2005) avaliou as imagens de destinos turísticos da Nigéria por meio do uso de fotografias e pesquisa estruturada. A pesquisa foi aplicada com 880 turistas nacionais e estrangeiros, por meio de uma amostra aleatória sistemática. As fotografias, de oito tipos de destinos turísticos, foram utilizadas como estímulo para avaliar as preferências de destino e as imagens considerados importantes na escolha do lugar pelos turistas. Os resultados revelaram que os destinos com natureza, vida selvagem e ecoturismo foram os tipos de destinos turísticos mais populares ou mais desejados pelos turistas. Enquanto que a baixa importância foi atribuída à segurança e aos componentes relacionados à qualidade dos serviços. O autor concluiu que a utilização de fotografias foi bastante eficaz para avaliar a 
importância atribuída às imagens de diferentes destinos turísticos da Nigéria.

Lo et al. (2011) identificaram o perfil dos turistas que postam fotografias on-line, comparando os usuários de diferentes plataformas. A pesquisa foi desenvolvida, analisando o uso de compartilhamentos de fotos de viagens on-line entre os residentes de Hong Kong. Por meio da análise de cluster, foram identificados cinco perfis de usuários que diferiram em tipo de mídia utilizada, perfil demográfico e motivação da viagem. Os autores concluíram que a maioria da amostra pesquisada utiliza as redes sociais virtuais, as mensagens instantâneas, os álbuns de fotos online e os blogs pessoais como principais meios para compartilhar fotos de viagens on-line.

Sheungting \& Mckercher (2015) expõem que as práticas fotográficas se tornaram foco de mais pesquisas nos últimos anos. Diante da preocupação com o uso da fotografia turística, os autores identificaram o processo de seleção e publicação das fotografias on-line. O processo apresentou cinco etapas, desde a tomada de decisão em levar uma câmera para a viagem, até a reflexão de postar as fotografias. O processo de seleção e publicação das fotografias on-line está intimamente ligado às impressões de cada indivíduo, com o mínimo de interação social, sendo que o significado das fotografias pode diferir de um público para o outro.

Já o estudo de Stepaniuk (2015) analisou se o fortalecimento do engajamento de usuários de mídia social, por meio da gestão de conteúdo inovador, poderia ser uma contribuição para a criação da imagem positiva dos destinos turísticos em meios de comunicação social. O método de levantamento diagnóstico foi utilizado para avaliar as preferências dos usuários em relação à natureza do conteúdo fornecido. O método heurístico também foi utilizado para desenvolver relações causais nas proposições do modelo. Os resultados sugerem que a estimulação comportamental e a criação de atividades comportamentais dos usuários de mídias sociais podem ser usadas para a construção da imagem a partir da utilização de fotografias relacionadas com o destino.

Para tanto, observou-se que a imagem influencia no processo de decisão para a escolha do destino turístico, e que o uso das redes sociais virtuais e das fotografias podem ser vistos como ferramentas de compartilhamento e de modificação da experiência turística. Diante disso, nesta investigação, busca-se avaliar a imagem do destino turístico Salvador, a partir das publicações na rede social de fotografia Instagram.

\section{PROCEDIMENTOS METODOLÓGICOS}

O presente estudo, de natureza exploratória, com caráter qualitativo e quantitativo, coletou imagens no Instagram, por meio do software Seekr Monitor, uma ferramenta para monitoramento e gestão das mídias sociais. A coleta de dados foi realizada, de forma aleatória, na rede social Instagram a partir da análise do conteúdo das fotografias.

Para Banyai e Glover (2012), a análise do conteúdo fotográfico é o método mais aplicado para examinar as imagens compartilhadas na mídia social, podendo transmitir as percepções visuais do destino e a criação de identidade. Para os autores, a análise do conteúdo fotográfico pode ser uma técnica subjetiva quando a observação e a interpretação das imagens são codificadas e ranqueadas de acordo com temas definidos pelo pesquisador.

Foram selecionadas 400 imagens marcadas no Instagram com a hashtag \#salvador. As imagens foram organizadas conforme a ocorrência de favoritas e para cada uma foi gerado um código numérico, entre -1 e 1 no Seekr Monitor, inserido por meio do recurso de tags, buscando facilitar a identificação das imagens para as análises. A amostra é não probabilística por conveniência. Conforme Malhorta (2012, p. 275), a amostra por conveniência "pode ser usada em pesquisa exploratória a fim de gerar ideias, intuições ou hipóteses”.

Para a categorização das imagens coletadas, foram utilizadas as dimensões de Baloglu e Mccleary (1999), que são as seguintes: Qualidade da experiência, atrações, valor ambiente - dimensões da imagem cognitiva; relaxar/escapar, aventura/ animação, conhecimento, social e prestígio dimensões motivacionais. Para a codificação das imagens, três pesquisadores do turismo avaliaram as imagens, desta forma, cada imagem foi avaliada três vezes de forma individual para assegurar uma imparcialidade. A partir da codificação numérica das imagens de acordo com as dimensões de Baloglu e McCleary (1999), foram ranqueados o número de curtidas e a quantidade de seguidores do perfil que publicou a fotografia, utilizando uma escala ordinal de 1 a 4 . 
Após a coleta de dados, no momento de interpretação das fotos, as informações foram transferidas para uma planilha no Microsoft Office Excel, e após foram importados para o pacote estatístico PASW Statistics 22 (SPSS). Dada a natureza da base de dados a explorar e os objetivos da pesquisa, foram utilizadas a análise de correlação não paramétrica de Spearman e a regressão linear múltipla.

A análise de correlação de Spearman é uma técnica utilizada para medir correlações não métricas (Malhorta, 2012). A regressão linear múltipla tem como objetivo, segundo Hair et al. (2009, p. 159), "usar as variáveis independentes cujos os valores são conhecidos para prever os valores da variável dependente selecionada pelo pesquisador".

Busca-se com essas análises avaliar as correlações entre o número de curtidas, o número de seguidores e as dimensões da imagem cognitiva e motivacionais para, posteriormente, avaliar a imagem do destino turístico Salvador (BA) projetada no Instagram.

\section{DISCUSSÃO DOS RESULTADOS}

Para as discussões e a apresentação dos resultados, serão apresentadas inicialmente as correlações entre as variáveis, depois serão apresentados os resultados do modelo proposto nesta pesquisa e, por último, serão discutidas quais dimensões da imagem do destino turístico Salvador (BA) tendem a receber mais curtidas no Instagram.

Tabela 01: Correlação de Spearmann

\begin{tabular}{|c|c|c|c|c|c|c|c|c|c|}
\hline & Curtidas & $\begin{array}{l}\text { Segui- } \\
\text { dores }\end{array}$ & $\begin{array}{l}\text { Quali- } \\
\text { dade }\end{array}$ & $\begin{array}{l}\text { Atra- } \\
\text { ções }\end{array}$ & $\begin{array}{c}\text { Valor/ } \\
\text { Ambiente }\end{array}$ & $\begin{array}{l}\text { Relaxar/ } \\
\text { Escapar }\end{array}$ & $\begin{array}{l}\text { Aven- } \\
\text { tura }\end{array}$ & $\begin{array}{l}\text { Conheci- } \\
\text { mento }\end{array}$ & Social \\
\hline Curtidas & 1,000 & & & & & & & & \\
\hline Seguidores & $0,619^{\star \star}$ & 1,000 & & & & & & & \\
\hline Qualidade & 0,077 & $0,125^{\star \star}$ & 1,000 & & & & & & \\
\hline Atrações & $-0,040$ & $-0,007$ & $0,434^{\star \star}$ & 1,000 & & & & & \\
\hline Valor/Ambiente & $0,181^{\star \star}$ & $-0,071$ & 0,086 & 0,070 & 1,000 & & & & \\
\hline Relaxar/Escapar & $0,169^{\star \star}$ & $-0,008$ & 0,010 & 0,003 & $0,509^{\star \star}$ & 1,000 & & & \\
\hline Aventura & $-0,050$ & $-0,023$ & $0,357^{\star \star}$ & $0,455^{\star \star}$ & 0,071 & $0,115^{\star}$ & 1,000 & & \\
\hline Conhecimento & $-0,108^{\star}$ & $-0,079$ & $0,340^{\star \star}$ & $0,690^{\star \star}$ & 0,045 & $-0,160^{\star \star}$ & $0,495^{\star \star}$ & 1,000 & \\
\hline Social & $-0,083$ & 0,039 & $0,264^{\star \star}$ & $0,350^{\star \star}$ & $-0,187^{\star \star}$ & $-0,345^{\star \star}$ & $0,371^{\star \star}$ & $0,437^{\star \star}$ & 1,000 \\
\hline $\begin{array}{c}\text { Prestígio } \\
\text { Fonte: Autores }\end{array}$ & $0,130^{\star \star}$ & $0,114^{\star}$ & $0,279^{\star \star}$ & $0,114^{\star}$ & $0,218^{\star \star}$ & $0,398^{\star \star}$ & $0,299^{\star \star}$ & 0,049 & $-0,107^{\star}$ \\
\hline \multicolumn{5}{|c|}{$\begin{array}{l}\text { A influência das dimensões da imagem do } \\
\text { destino turístico Salvador (BA), no Instagram, foi } \\
\text { testada por meio de regressão linear múltipla, na } \\
\text { qual as dimensões da imagem, adaptadas de Baloglu } \\
\text { e Mccleary (1999), foram utilizadas como variáveis } \\
\text { independentes (preditoras) e o número de curtidas } \\
\text { foi utilizado como variável dependente (critério). }\end{array}$} & \multicolumn{5}{|c|}{$\begin{array}{l}\text { Foi realizada uma análise de regressão linear } \\
\text { múltipla pelo método "enter", na qual todas as } \\
\text { variáveis são incluídas ao mesmotempono modelo. } \\
\text { O resultado, conforme se vê na Tabela 02, aponta } \\
\text { a existência de relações positivas e negativas entre } \\
\text { as dimensões da imagem do destino turístico e o } \\
\text { número de curtidas no Instagram. }\end{array}$} \\
\hline
\end{tabular}
pode-se destacar as relações positivas entre as dimensões: conhecimento e atrações $(0,690)$, relaxar/escapar e valor ambiente (0,509), conhecimento e aventura $(0,495)$, aventura e atrações $(0,455)$, social e conhecimento $(0,437)$, atrações e qualidade $(0,434)$. Para Baloglu e McCleary (1999), as dimensões conhecimento, prestígio e social têm um impacto direto na imagem do destino, ao contrário da aventura que tem um impacto indireto. Conforme os resultados desta pesquisa, notou-se que a aventura está correlacionada ao conhecimento e às atrações. Isto significa que, mesmo que não tenha um impacto direto na imagem, a dimensão aventura tem uma relação forte com estas outras dimensões. Em termos práticos, a aventura fortalece o impacto direto por meio do conhecimento e das atrações.

A partir da matriz de correlação de Spearman entre o número de curtidas, o número de seguidores e as dimensões da imagem, foi possível avaliar o alinhamento semântico entre eles. Como era esperado, existe correlação positiva entre seguidores e curtidas $(0,619)$. Este resultado indica que os usuários do Instagram que têm mais seguidores tendem a ter também mais curtidas. Além disso, as dimensões da imagem conhecimento e atrações são as que apresentam maior correlação entre si, mostrando que as imagens de Salvador que demonstram experiências em lugares novos e diferentes ou, ainda, imagens de atrações históricas e culturais, tendem a ser avaliadas positivamente pelos usuários do Instagram. 
Tabela 02: Regressão linear múltipla

\begin{tabular}{|c|c|c|c|c|c|c|}
\hline & & \multicolumn{2}{|c|}{$\begin{array}{l}\text { Coeficientes não } \\
\text { padronizados }\end{array}$} & $\begin{array}{l}\text { Coeficientes } \\
\text { padronizados }\end{array}$ & \multirow[b]{2}{*}{$t$} & \multirow[b]{2}{*}{ Sig. } \\
\hline & $\begin{array}{c}\text { Modelo } \\
\text { B }\end{array}$ & $\begin{array}{l}\text { Modelo } \\
\text { padrão }\end{array}$ & Beta & & & \\
\hline \multirow[t]{9}{*}{1} & (Constante) & 0,036 & 0,005 & & 7,122 & 0,000 \\
\hline & Qualidade & 0,017 & 0,019 & 0,047 & 0,923 & 0,357 \\
\hline & Atrações & $-0,013$ & 0,009 & $-0,096$ & $-1,466$ & 0,143 \\
\hline & Valor ambiente & 0,024 & 0,011 & 0,119 & 2,231 & 0,026 \\
\hline & Relaxar/Escapar & 0,020 & 0,011 & 0,104 & 1,760 & 0,079 \\
\hline & Aventura & 0,017 & 0,010 & 0,096 & 1,640 & 0,102 \\
\hline & Conhecimento & 0,003 & 0,011 & 0,018 & 0,265 & 0,791 \\
\hline & Social & $-0,008$ & 0,008 & $-0,051$ & $-0,937$ & 0,349 \\
\hline & Prestígio & $-0,051$ & 0,011 & $-0,253$ & $-4,697$ & 0,000 \\
\hline
\end{tabular}

Fonte: Autores

$\mathrm{Na}$ análise realizada encontrou-se um modelo constituído por duas variáveis e uma constante. $\mathrm{O}$ resultado do teste F-ANOVA com significância zero $(\mathrm{p}<0,05)$ permite afirmar que a hipótese de que $\mathrm{R}^{2}$ é igual a zero pode ser rejeitada. Isso posto, é possível afirmar que as variáveis preditoras (valor ambiente e prestígio) possuem influência sobre a variável dependente (números de curtidas no Instagram), e o modelo como um todo, evidenciando ser significativo.

O resultado reforça a importância da dimensão valor/ambiente e da dimensão prestígio nas imagens, haja visto que, entre as dimensões, foram as únicas que significativamente influenciam na quantidade de curtidas por seguidor. Os gestores devem procurar imagens que agreguem valor ao ambiente para atrair turistas para Salvador (BA). O resultado da dimensão prestígio corrobora com a pesquisa de Baloglu e McCleary (1999) quanto à influência significativa desta dimensão na formação da imagem, entretanto, no caso de Salvador (BA), a influência é negativa.

A partir da análise da Tabela 02, nota-se que, das oito variáveis lançadas como independentes, apenas duas permaneceram na análise compondo o modelo final. A imagem geral do destino turístico Salvador (BA) é explicada pela seguinte modelo.

Figura 1. Modelo Imagem de Salvador (BA) no Instagram.

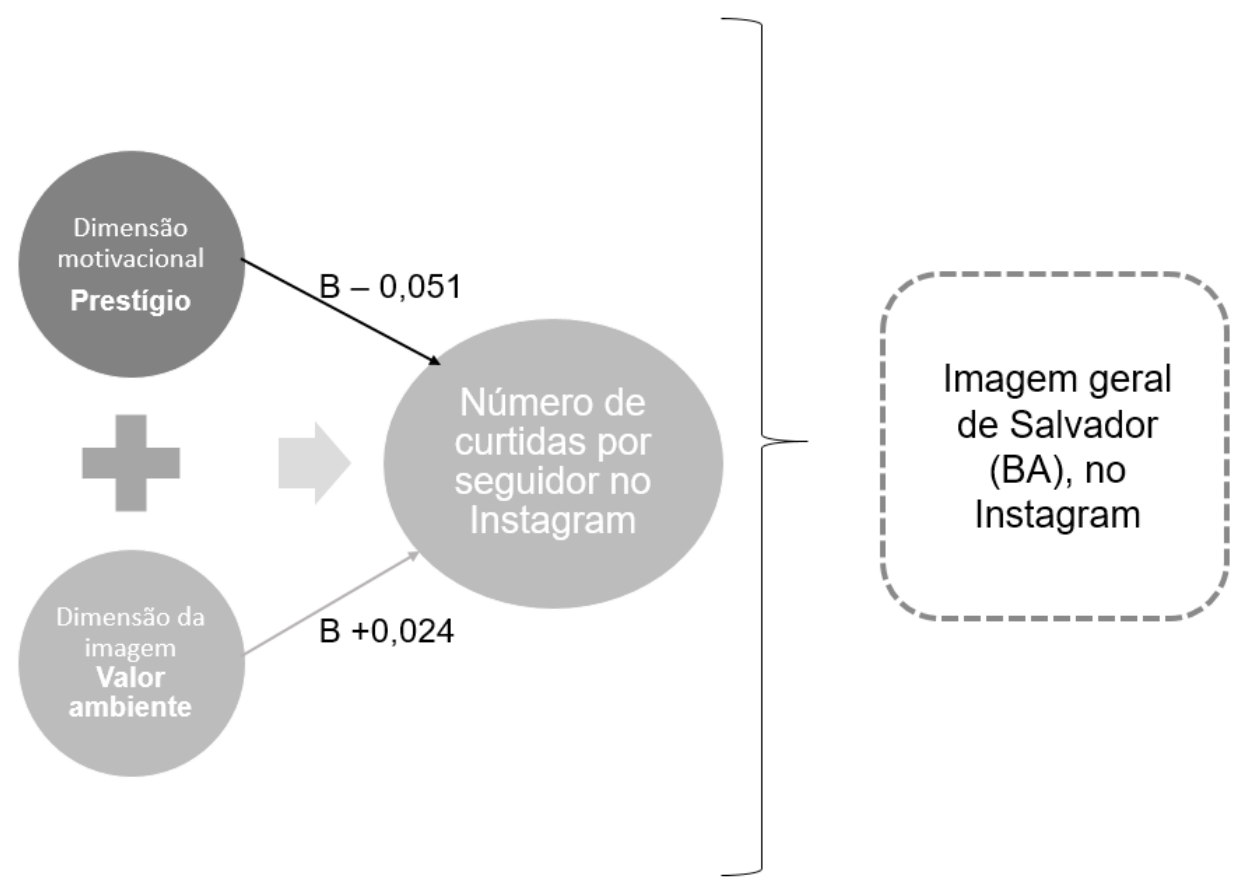

Fonte: Autores. 
Diante do modelo estimado, verifica-se que o "prestígio" é a dimensão da imagem do destino turístico que contribui de forma negativa para composição do número de curtidas e, consequentemente, para a formação da imagem do destino no Instagram. Quanto mais as pessoas postam fotos de Salvador para exibir aos outros a visita ao destino, o número de curtidas e a propagação da imagem no Instagram tende a diminuir $(5,1 \%)$. Por outro lado, notou-se que o "valor ambiente" é a dimensão da imagem de Salvador (BA) que contribui de forma positiva para o incremento do número de curtidas na rede social de fotografia. As fotos que expõem a relação custo/ benefício do destino, ambiente não poluído e clima agradável, são as que contribuem com 2,4\% para a elevação do número de curtidas por seguidor no Instagram. Para tanto, constata-se que quanto mais o destino turístico Salvador (BA) direcionar seus esforços promocionais nas redes sociais virtuais, envolvendo os aspectos de valor ao ambiente, serão mais efetivos do que comercializar o destino por meio dos apelos ao prestígio.

Este resultado corrobora com a pesquisa de Awaritefe (2005), que identificou que os destinos turísticos com imagens da natureza e da vida selvagem (ambiente) foram os mais populares entre os participantes, além de ratificar a importância da dimensão motivacional (prestígio) para compreender a imagem do destino turístico, já identificada no estudo de Baloglu e McCleary (1999).

A formação da imagem de Salvador (BA) demonstra a complexidade de fatores que os gestores precisam considerar quando vão transmitir a imagem de um destino. $\mathrm{O}$ ambiente contribui na formação da imagem, sendo a dimensão que tem um impacto positivo nas curtidas das imagens. Os resultados deste trabalho precisam ser considerados pelos gestores do destino para que possam alinhar as dimensões exploradas nas imagens com os objetivos do plano de comunicação.

\section{CONSIDERAÇÕES FINAIS}

A presente investigação contribui teórica e empiricamente com as discussões sobre a formação da imagem de destino turístico projetada nas mídias sociais virtuais. Os procedimentos metodológicos adotados conseguiram fazer com que o objetivo proposto fosse atingido. Por meio de análise de regressão linear múltipla, foi avaliada a projeção da imagem turística de Salvador (BA) no Instagram.
Os resultados mostraram que o prestígio exerce influência negativa para a formação geral da imagem do destino turístico, enquanto o valor ambiente é a dimensão da imagem que contribui de forma positiva para o incremento do número de curtidas na rede social de fotografia e projeção da imagem do destino.

O estudo fornece contribuições teórica e empírica ao tema, ao avaliar que apenas a dimensão da imagem cognitiva - valor ambiente; e a dimensão motivacional - prestígio, ambas adaptadas de Baloglu e McCleary (1999), influenciam a formação geral da imagem do destino turístico Salvador (BA), a partir das fotografias publicadas na rede social Instagram. Essas contribuições servirão para o avanço do conhecimento científico sobre a relação entre os construtos: imagem de destino, redes sociais virtuais e fotografias. Ademais, os resultados apresentam implicações práticas para que as DMOs, os gestores públicos e privados do destino turístico Salvador (BA) possam formular estratégias mais efetivas para $\mathrm{O}$ posicionamento e a comunicação da imagem do destino turístico.

A pesquisa não tem a pretensão de esgotar o assunto e por isso os autores encorajam a realização de outros estudos sobre os mesmos construtos, em outros contextos. Para pesquisa futura, sugere-se que o modelo seja replicado, buscando a hashtag de outros destinos turísticos, a fim de avaliar a imagem turística e propor contribuições gerenciais.

\section{REFERÊNCIAS BIBLIOGRÁFICAS}

Abdel, H., Fayed, K., Wafik, G. M., \& Gerges, N. W. (2016). The Impact of Motivations , Perceptions and Satisfaction on Tourists' Loyalty, 9(2), 14-26.

Awaritefe, O. D. (2005). Image Difference Between Culture and Nature Destination Visitors in Tropical Africa: Case Study of Nigeria. Current Issues in Tourism, 8(5), 363-393. https://doi. org/10.1080/13683500508668224

Baloglu, S., \& McCleary, K. W. (1999). A model of destination image formation. Annals of Tourism Research, 26(4), 868-897. https://doi.org/10.1016/ S0160-7383(99)00030-4

Banyai, M., \& Glover, T. D. (2012). Evaluating research methods on travel blogs. Journal of Travel Research, 51(3), 267-277.

Beerli, A., \& Martín, J. D. (2004). Factors influencing destination image. Annals of Tourism Research, 31(3), 657-681. https://doi.org/10.1016/j. annals.2004.01.010

Buhalis, D. (2000). Marketing the competitive 
destination of the future. Tourism Management, 21(1), 97-116. https://doi.org/10.1016/ S0261-5177(99)00095-3

Chagas, M. M. (2008). Imagem de destinos turísticos: Uma discussão teórica da literatura especializada. Revista Turismo Visão e Ação. v 10, n 3, p. 435 $-455$.

Chi, C. G. Q., \& Qu, H. (2008). Examining the structural relationships of destination image, tourist satisfaction and destination loyalty: An integrated approach. Tourism Management, 29(4), 624-636. https://doi.org/10.1016/j.tourman.2007.06.007

Crompton, \& McKay, S. L. (1997). Motives of Visitors Attending Festival Events. Annals of Tourism Research, 24(2), 425-439. https://doi.org/10.1016/ S0160-7383(97)80010-2

Fodness, D. (1994). Measuring tourist motivation. Annals of Tourism Research, 21(3), 555-581. https:// doi.org/10.1016/0160-7383(94)90120-1

Gartner, W. C. (1993). Image Formation Process. Journal of Travel \& Tourism Marketing, 2(2-3), 37-41. https://doi.org/10.1300/J073v02n02

Hair Jr., J. F.; Anderson, R. E.; Tatham, R. L. \& Black, W. C. (2005). Análise multivariada de dados. Porto Alegre: Bookman.

Lo, I. S., Mckercher, B., Lo, A., Cheung, C., \& Law, R. (2011). Tourism and online photography. Tourism Management, 32(4), 725-731. https://doi. org/10.1016/j.tourman.2010.06.001

MacKay, K. J., \& Fesenmaier, D. R. (1997). Pictorial Element of Destination in Image Formation. Annals of Tourism Research, 24(3), 537-565. https:// doi.org/10.1016/S0160-7383(97)00011-X

Martín Gutiérrez, H. S., \& del Bosque, I. R. (2010). Los factores estímulo y personales como determinantes de la formación de la imagen de marca de los destinos turísticos: un estudio aplicado a los turistas que visitan un destino vacacional. Cuadernos de Economía y Dirección de la Empresa, 13(43), 37-63. https://doi.org/10.1016/S1138-5758(10)70009-8

Olague, J. T. (2016). Efecto determinante de la motivación de viaje sobre 1_a imagen de destino en turistas de ocio a un destino urbano: el caso de monterrey, méxico. una a proximación por medio de $\mathrm{m}$ ínimo s cuadrados parciales (PLS). RevistaTurismo y Sociedad, xviii, 61-78. https://doi. org/https://doi.org/10.18601/01207555.n18.04

Pike, S. (2007). Destination Image Literature - 2001 to 2007. Acta Turistica, 19(2), 101-228.

Sheungting, I., \& Mckercher, B. (2015). Annals of Tourism Research Ideal image in process : Online tourist photography and impression management. Annals of Tourism Research, 52, 104-116. https://doi. org/10.1016/j.annals.2015.02.019

Singh, N., \& Formica, S. (2006). Level of Congruency in Photographic Representations of Destination Marketing Organizations' Websites and Brochures.
Journal of Hospitality \& Leisure Marketing, 15(3), 7186. https://doi.org/10.1300/J150v15n03 05

Stepaniuk, K. (2015). The relation between destination image and social media user engagement theoretical approach. Procedia - Social and Behavioral Sciences, 213, 616-621. https://doi.org/10.1016/j. sbspro.2015.11.459

Whang, H., Yong, S., \& Ko, E. (2016). Pop culture destination images, and visit intentions: Theory and research on travel motivations of Chinese and Russian tourists. Journal of Business Research, 69(2), 631-641. https://doi.org/10.1016/j. jbusres.2015.06.020

Pesquisa financiada pelo projeto MCTI/CNPQ/ Universal 14/2014, denominado "Modelo de referência para a análise da imagem de destino turístico projetada nas mídias sociais virtuais”.

\section{Contribuição dos autores}

Fabrícia Durieux Zucco: Desenvolvimento do artigo.

Melise de Lima Pereira: Desenvolvimento do artigo.

Pablo Flôres Limberger: Desenvolvimento do artigo.

Christian Daniel Falaster: Desenvolvimento do artigo. 